\title{
EL FIN DE SIGLO Y LOS ESCRITORES DE LA RESTAURACIÓN
}

El fraccionamiento y la quiebra del naturalismo en Francia coinciden con una universalización del horizonte literario, primero con la novela rusa y poco después con la eclosión de gustos y tendencias que traen las corrientes literarias englobadas en la nada exacta expresión de decadencia. A estas alturas de fin de siglo se considera la influencia de Zola como en gran parte acabada, y su fórmula novelística, válida todavía para su creador, aparece sin viabilidad estética y sin vigencia para los demás. Frente al positivismo de Comte, que habia prescindido de lo religioso y de lo metafísico como conceptos inválidos, sustituyéndolos por el cientificismo que se venía aplicando a la misma estética literaria, se produce ahora una especie de complacencia en los aspectos espirituales y psicológicos de la vida. El mismo fondo de pesimismo $y$ de angustia vital que hay en la nueva literatura es consecuencia tanto del fracaso de la fe en la ciencia, como de la orientación antirracionalista que se manifiesta en tendencias espiritualistas y místicas de varia y hasta opuesta naturaleza. De todos modos, la actitud más típica del hombre fin de siècle es, por un lado, la insatisfacción, la inquietud, llevada a veces a la perversión erótica, la aniquilación individual y, por otro, el reconocimiento de una realidad trascendente que genera crisis religiosas e incluso conversiones. Ahora dejan la escena las gentes menos cultas de la sociedad industrial -el cuarto estado-, para dar entrada a las clases ilustradas y de hombres ultra-refinados. La novela aristocrática y psicológica, que vive un momento de eclosión en este período (Bourget), así como el resurgimiento de la novela novelesca o idealista, incluso mística, en la que Brunetière y nuestro Clarín veían la novela del porvenir, son el signo de los tiempos y responden a la sensibilidad fin de siglo.

Pardo Bazán, que había tomado el pulso a esta literatura en París, reafirma, muchos años después, que "en una hora de decadencia, fue decadente, y no podía ser otra cosa. En un mundo mo- 
ralmente enfermo, fue morbosa, mostró lesiones generales de todo el organismo". Nuestra escritora continúa identificando en lo posible las formas y direcciones variadísimas que puede adoptar esta literatura asistemática y antisocial por naturaleza, tales como "el misticismo, el simbolismo, el satanismo, el sadismo, el sobrenaturalismo, la poetización de lo nefando, la magia negra, el espiritismo, el hermetismo, el ocultismo, el erotismo cerebral, y hasta, literariamente, el gongorismo, y lo que, con gracia, se ha llamado el oscurismo". En particular, se siente atraída por el espiritualismo católico que, torcido y todo, hay en algunas de estas tendencias y que muestra un fondo de que carecía la obra de Zola: "un catolicismo, no diré que tal cual lo aprobaría un obispo algo escrupuloso, pero catolicismo al fin, opuesto al racionalismo y mirando al materialismo con náusea y horror"1.

Estéticamente hablando, uno de los errores de Zola había estado en que, al presentar a sus héroes despojados del sentido de lo sobrenatural y religioso en sus vidas, de lo impredecible y de lo maravilloso en sus acciones, los había degradado hasta el punto de no ser libres ni responsables de su propio destino. Esta falta de criterio artístico le había llevado a un exagerado culto a la realidad fenoménica y experimental, a la vez que marginaba totalmente esa otra realidad interior que el hombre lleva consigo, "esa realidad sumergida en lo desconocido", en frase de Clarín, que da la clave al arte para interpretar, hasta cierto punto, los grandes porqués de la aventura humana. Tan es así, que el mismo Zola liega a sentir la profundidad del problema, pues la ola de espiritualismo y misticismo nebuloso que se alza en algunos de los nuevos ismos no le pasa desapercibida". Y aunque él "no se cree influido por ella", como dice Clarín, "en las recientes novelas (en Le Rêve, L'Argent y La Débâcle) se puede notar que el artista tiende, como otros, a una poesía ideal, misteriosa, metafísica, de una psicología más profunda y más íntima que la que puede engendrarse de la hipótesis psicofísica y de los procedimientos de fuera a dentro del empirismo fisiológico positivista"'s.

Por lo que se refiere a España, el sesgo que desde un principio toma el naturalismo, la preserva en gran medida de que se dé una

1 Porvenir de la literatura después de la guerra, Madrid, 1917, pp. 27-28.

2 En unas declaraciones de Zola, que recoge Clarín, sobre las nuevas tendencias, el corifeo de la novela experimental dice que "es indudable que en literatura, como en otros órdenes, se nota cierta tendencia mística, y aunque él no la sigue $y$ se aferra a su positivismo pesimista, reconoce la importancia de esa expansión del espíritu moderno y la ve con interés $y$ sin antipatía" (Palique, Madrid, 1893, pp. 167-168).

3 Ibid., pp. 168-169. 
tal anarquía de gustos y de tendencias como en Francia. Concretándonos a la generación de la Restauración, el naturalismo sigue en ella un camino muy distinto al de Francia. Empleado aquél desde un principio con múltiples reservas y aditivos, que lo habian cambiado casi por completo de fisonomía, evoluciona decididamente, dentro de la gran corriente realista nacional, hacia formas espirituales. Cuando a finales de siglo las nuevas generaciones francesas dan la última batalla al naturalismo, en España el vitalismo humanista y cristiano de nuestros escritores de la Restauración ya había ganado la suya al abarcar una realidad a la vez material y espiritual. Por cierto, esta propensión espiritualista del naturalismo español es en rigor genuinamente nacional, y no puede explicarse como una influencia de la literatura rusa sino en cuanto ésta goza de prelación en lo que terminó siendo una tendencia general. Desde esta óptica, cabe entender la crisis posnaturalista de la novela en España -que en parte coincide con la entrada en escena de la generación del 98 - más bien como producto del revisionismo español que de un agotamiento real del género en la generación precedente. Es dato decisivo -que la crítica regeneracionista del 98 se negó a reconocer- la obra de Galdós en su fase de fin de siglo. Señala ésta el momento de su plenitud artística al ofrecer uno de los más claros ejemplos de interiorización en la sustancia narrativa y al iniciar, antes que los mismos generacionistas, un movimiento de rebeldía frente a la limitada fórmula literaria que hasta entonces había empleado el realismo español. Queremos decir que, cuando los del 98 comienzan a echar mano de la imaginación y de la perspectiva psicológica como catalizadores de la realidad literal a la que por tradición se venía anclando excesivamente el relato en España, estos rasgos eran ya un hecho en la creación galdosiana e incluso en la de Pardo Bazán, Clarín y Palacio Valdés. Se puede decir que es todo un descubrimiento de lo que hay de más actual en Galdós lo que lleva a efecto Ricardo Gullón al llamarlo "novelista moderno". Porque por el asombroso impulso que da a su novela y el aliento modernamente audaz de sus técnicas en esta fase, Galdós admite parangón con autores de nuestros días. Lo mismo habría que decir - aunque conservando la distancia que los separa- de Pardo Bazán. Lo que pasa es que está por escribir un estudio de conjunto sobre nuestro realismo en uno de sus momentos de plenitud, representado en la prodigiosa floración de novelas que componen el panorama de fin de siglo. Obras como Ángel Guerra, Nazarín y Misericordia, de Galdós, La quimera y La sirena negra, de Pardo Bazán, se han estudiado sólo fragmentariamente. Estas obras no son tanto una suma de anécdotas y una objetiva enumeración del mundo visible cuanto una apremiante preocupa- 
ción por un mundo intuido; son más bien una exploración de almas que una mera reproducción de fisonomías.

Las nuevas corrientes espiritualistas que surgen en el campo literario, primero con la novela rusa y casi a la vez con las fórmulas decadentistas, son ciertamente seguidas en España con viva curiosidad e interés por los escritores de la Restauración, aunque la influencia que ejercen sobre algunos de ellos es ideológica y estéticamente menor. En el fondo, esto se debe a que la tendencia naturalista en algunos, como Galdós y Pardo Bazán, está concebida desde el principio como una fórmula abierta a reformas y modificaciones. El naturalismo modo hispano continúa en ellos depurándose a través de lo que podemos considerar como un anhelo de espiritualidad y de psicologización. Naturalmente, esta evolución dentro del realismo tal y como aparece en algunos de nuestros escritores, aunque no se mantiene totalmente al margen de las corrientes de fin de siglo, discurre por canales propios ya que es la interpretación de la época y del medio social españoles de acuerdo con una óptica peculiar. Así, Menéndez Pelayo, aludiendo al carácter evolutivo de signo religioso de la obra de Galdós, especialmente en Ángel Guerra, opina que "algo ha podido influir en esta nueva dirección del talento de Galdós el ejemplo del gran novelista ruso Tolstoi; pero más ha de atribuirse este cambio a la depuración progresiva ... de su propio pensamiento religioso"4. Y Pardo Bazán, al hacer la crítica de esta novela, señala de pasada que "parece proceder de alguna de las mejores inspiraciones de Tolstoi"'s, frase que más bien sugiere coincidencias fortuitas que una determinada fuente de influencia.

Además, el naturalismo español, "el verdadero" que dice Clarín, sigue vigente "porque es algo más que una moda" nión, este naturalismo continúa siendo una "fórmula legítima" que le parece "oportuno ... seguir alentando ... con las atenuaciones que imponga el genio variable de nuestro pueblo... y con las que vayan indicando estas últimas corrientes". Dice también que Realidad, la novela de Pérez Galdós, le ha parecido "un reflejo español de esa nueva etapa"?. Galdós, a su vez, en el prólogo a la tercera edición de La Regenta, escrito en 1901, dice que la novela de Clarín, "muestra feliz del naturalismo restaurado" gozando de actualidad.

4 Discursos leidos ante la Real Academia Española: Menéndez Pelayo, Pereda y Pérez Galdós, Madrid, 1897, pp. 90-91.

5 Obras completas, Madrid, 1973, t. 3, p. 1101.

6 Galdós, Madrid, 1912, pp. 155-156.

7 Ibid., pp. 207-208.

8 Obras completas, Madrid, 1961, t. 4, p. 1448. 
No hay que perder esto de vista para entender la época de fin de siglo; mientras en otros países es de confusión y de inquietud, en España, a juicio de Galdós, es a pesar de todo una época propicia al "florecimiento literario". Piensa que en la nueva narrativa "a medida que se borra la caracterización general de cosas y personas quedan más descarnados los modelos humanos, y en ellos debe el novelista estudiar la vida para obtener frutos de un Arte supremo y durable ... Perdemos los tipos, pero el hombre se nos revela mejor, y el Arte se avalora sólo con dar a los seres imaginarios vida más humana que social. Y nadie desconoce que, trabajando con materiales puramente humanos, el esfuerzo del ingenio para expresar la vida ha de ser más grande y su labor más honda y difícil"'. De esta manera viene Galdós a subsanar lo que él mismo considera fue una visión incompleta en el naturalismo de escuela, el cual había mostrado "un cierto desprecio de los resortes imaginativos y de la psicología espaciada y soñadora" 10 , tan necesarios para explorar las vivencias del "alma social" y de la personalidad humana.

Dentro de este mismo contexto, Pardo Bazán, aunque no se fía de la sinceridad de propósitos de la generación francesa de fin de siglo en la que ve un reflejo del viejo romanticismo, dice que prefiere "una decadencia con carácter y con afán de buscar rumbos nuevos, a una estancación o a una esterilidad"11. Comprende doña Emilia que ahora en Francia, donde se ha "encanallado" el naturalismo, los escritores se hayan cansado de él y ansien la vuelta a lo que ella considera como un tipo de novela idealista y romántica; otro es, sin embargo, el caso de España, "donde el terreno estaba mejor preparado, porque no tenía el naturalismo sistemático antecedentes tan gloriosos"12. Por esto es que en España "no se han escrito novelas documentarias, sino novelas realistas, enlazando la tradición rancia y venerable de nuestra novela en los siglos xvi y xvn, con lo poco de espíritu moderno que llegó hasta nosotros. Nuestra novela actual ni peca de obscena y cruda, ni menos de cruel. No se justificaría aquí ese cansancio del público harto de fealdades, hiponcondrías y horrores, de que hablan Olmet y Bonniéres"'13. Además, la influencia que las nuevas corrientes pue-

9 Discursos leidos ante la Real Academia Española.., pp. 24-25.

10 Obras completas, t. 6, p. 1448.

11 Cuarenta dias en la exposición, Madrid, s. f., p. 41. Para mayor abundancia y precisión sobre la actitud crítica de la Pardo Bazán frente al decadentismo véase el artículo de Jorn W. Kronik, "Emilia Pardo Bazán and the phenomenon of French decadentism", PMLA, 81 (1966), 418-427.

12 Nuevo teatro critico, 13 (1892), p. 76.

13 Ibid., 6 (1891), p. 41. 
dan ejercer en España nunca será funesta porque, como había sucedido anteriormente con el naturalismo, "los países dueños de la robusta tradición nacional, siempre sabrán dar forma propia a lo que les venga de fuera" ${ }^{14}$. Ya en 1891 Pardo Bazán llega a decir que las nuevas tendencias no podrían sobrevivir en España donde la corriente espiritualista tiene antecedentes más ortodoxos que en el país vecino; tan es así que "si por acá despuntase un Péladan -dice-, le juzgaríamos probablemente lunático, estrafalario, sortílego y digno de ser encerrado en Leganés. Además, aun cuando por acá no nos luce el pelo, ni estamos muy boyantes, no sé si por virtud de nuestro hermoso cielo o de que la falta de bienes positivos aligera el ánimo y fortalece el corazón, ello es que no andamos tan desesperados como en Francia, ni somos tan rabiosamente pesimistas, ni sentimos lo que hasta los gatos llaman ya la «melancolía de fin de siglo», ni tenemos ese misticismo empecatado, ni esas «elegantes corrupciones»"15. Considera que Bourget, "el jefe de la escuela psicológica" 16 y "el talento más cultivado y robusto de la nueva generación"17, no tiene grandes dotes de novelista; la última novela de Huysmans le parece "sacrilega, demoníaca y obscena" (ibid., p. 99), y a Barrès, que viene a España "a formarse alguna idea, sobre el terreno, de nuestros escritores místicos" (ibid., p. 102), no logra entenderlo en la entrevista que sostiene con él en Madrid. Doña Emilia apunta a las dos causas que, en su opinión, ocasionan la oscuridad de Barrès: "inconsecuencia del pensamiento y deficiencia de la forma artística al expresarlo" (ibid., p. 105). Cuando en 1917, desde una perspectiva más amplia, enjuicia Pardo Bazán la bancarrota que había sufrido el naturalismo en Francia a los duros golpes del neoromanticismo idealista, sigue pensando que la literatura había iniciado en la propia Francia una fase de decadencia "porque no surgían, ni en tanta cantidad ni dotadas de tanto vigor, las personalidades literarias" ${ }^{18}$, como durante el período realista-naturalista.

Por otra parte, más convencía a Pardo Bazán la reacción espiritualista del naturalismo ruso, naturalismo ciertamente pero "con ventanas y respiración, sin pseudo-ciencia y sin positivismo barato"19. Naturalmente, esta reacción que se había propagado a Francia y de ahí a diversos países, entre ellos España, "era algo distinto del misticismo decadente: era un sentido religioso enlazado estrecha-

14 La Revolución y la novela en Rusia, Madrid, 1961, p. 30.

15 Vida contemporánea, Madrid, 1896, p. 28.

16 Nuevo tcatro critico, loc, cit., p. 64.

17 Ibid., 19 (1892), p. 82.

18 Portenir de la literatura después de la guerra, p. 18.

10 La literatura francesa moderna, t. 3, Madrid, s. a., p. 113. 
mente con el social y patriótico, por el cual volvian las cigüeñas a los campanarios"' 20 . El catolicismo de la condesa no le impide descubrir bajo las inaceptables ideas nihilistas de los autores rusos la realidad sustantiva de un renacimiento religioso y humano muy conforme con su propia sensibilidad. Tal sucede en las desconcertantes antinomias dostoyevskianas, "donde lo horrible es bello, lo desesperado consuela, lo innoble raya en lo sublime; donde las rameras enseñan el Evangelio, los hombres van a la regeneración por el camino del crimen" 21 . Se siente especialmente atraída hacia el misticismo de Tolstoi a quien "desde la niñez le tortura y acongoja el misterio de las cosas y el más allá, o sea el ilimitado horizonte de lo divino" (ibid., p. 251), hasta que, tras una terrible crisis psico-religiosa, se convierte a una forma de cristianismo social aunque ciertamente no menos anarquista $e$ insostenible que su ideología nihilista anterior.

Fue, sin duda, y continúa siendo apasionante problema averiguar la existencia y extensión de una influencia más o menos inmediata de los novelistas rusos, en especial de Tolstoi, en Galdós y en Pardo Bazán, entre otros. Aunque el principio de originalidad no es incompatible con la existencia de fuentes de inspiración, siempre que no se degenere en servil dependencia, la pretensión de señalar esas fuentes tiene sus riesgos. En el caso concreto que nos ocupa, y mientras no se llegue a conclusiones más definitivas, hay que evitar los extremos tanto de los partidarios de una influencia sustancial foránea en estos escritores, como de los defensores de una originalidad a ultranza que sitúa sus obras en un contexto exclusivamente nacional. A este tenor dice Pardo Bazán que "apropiarse los ideales modernos en lo que tienen de hondo y de serio y de decisivo, no sería extranjerizarse, sino humanizarse"22. Esto, a su vez, demuestra que las pretendidas influencias y deudas con frecuencia no son sino concomitancias, no del todo fortuitas porque responden a corrientes ideológicas y estéticas del patrimonio universal. Además, Galdós y Pardo Bazán, al comenzar la última década del siglo, tienen una vasta producción narrativa en su haber; por aquellas fechas ya son maestros experimentados en el arte de novelar y están iniciando una fase, la más original, a la que han llegado por un proceso de maduración artística en el que no podría afirmarse, sin clara arbitrariedad, que sufrieran fantásticas influen$\operatorname{cias}^{23}$, como no fueran las sociales y estéticas a que obedecían

20 Porvenir de la literatura después de la guerra, p. 34.

21. La Revolución y la novela en Rusia, p. 227.

22 De siglo a siglo, Madrid, s. f., p. 168.

23. Joaquín Casalduero, en Estudios de literatura española (Madrid, 1967, pp. 179-201), recliaza como "incorrecta" la teoria de George Portnoff (véase 
orientaciones semejantes en otros países, y no precisamente las de un determinado escritor. Se ha esgrimido el dato de que en cierta ocasión la condesa observa irónicamente que Pereda, representante epónimo del regionalismo, "no siente esa necesidad de renovación que nos empuja, no ya hacia Madrid, sino mucho, mucho más allá, iquién sabe si hasta Rusia!'"24. Y, sin embargo, hay que interpretar la reticencia de doña Emilia no en su literalidad, es decir, como una espontánea confesión de fuentes allende nuestras fronteras, sino como una evasión intencionada del tema. De hecho, en su extensa obra crítica no hay estudio alguno sobre la influencia de la literatura rusa en los escritores españoles de su generación, lo cual es bien significativo. Inevitable resulta recordar aquí las conferencias de Pardo Bazán en el Ateneo en 1887, las cuales dan a conocer el naturalismo espiritualista ruso al público español ${ }^{25}$. Incluso Galdós, refiriéndose a ellas, dice que "son el acontecimiento del día", y que "de Francia el filorrusismo va cundiendo a las naciones vecinas" ${ }^{26}$, pero en ningún momento se considera a sí mismo incluido ${ }^{27}$. Por otra parte, fácil es advertir que la novela rusa deja poca huella en España. Ya en 1892 advierte Clarín que incluso en Francia "el prurito rusófilo no ha sido más que un arranque del

su obra La literatura rusa en España, New York, 1932, pp. 132-171) que se pronuncia por una influencia genética de Ana Karenina en Realidad, de Galdós. Los estudios más recientes de VEra Colrs, "A note on Tolstoy and Galdós", $A G, 2$ (1967), 155-168, y "Tolstoy and Angel Guerra", en GS, 1, prueban que, a pesar de los múltiples elementos de clara ascendencia tolstoiana en Ángel Guerra, Nazarin y Halma, Galdós sigue un método interpretativo propio y llega a conclusiones distintas de las del escritor ruso. Al parecer Galdós estuvo en contacto con la obra de Tolstoi, y en general con la literatura rusa, desde una fecha difícil de precisar pero ciertamente anterior a 1887, en que asiste con asiduidad al ciclo de conferencias sobre "La Revolución y la novela en Rusia" que Pedro Bazán da en el Ateneo de Madrid. Posteriormente Galdós mantiene con Tolstoi una correspondencia cuyo contenido no ha sido aún revelado.

24 Polémicas y estudios literarios, Madrid, s. f., p. 27.

25 Ronald Hilton, uno de los críticos que más temprana y perspicazmente ha estudiado la obra de Pardo Bazán en su relación con otras literaturas, refiriéndose en concreto a la traducción inglesa de La Resolución y la novela en Rusia (Chicago, 1890), destaca la importancia de esta obra "in arousing American interest in Russian studies" ("Doña Emilia Pardo Bazán, a pioneer of Russian studies", American Slavic and East European Review, 11 (1952), p. 215).

26 Arte y critica, t. 2, Madrid, 1923, pp. 203 y 207.

27 Bien conocida es la actitud de Galdós de rechazar fuentes e influencias en su obra. En su sentir España es una cantera inextinguible de esplritualismo que puede abastecer al mundo entero, como dice por boca de un personaje en Halma, parte $3^{7}$, II, texto que algunos consideran como un rechazo frontal de la influencia rusa por parte del escritor. 
neurosismo, del boulevard, algo ficticio y que ya empieza a decaer". $Y$ añade que "el amor a las letras rusas ... obedecía y obedece a causas ajenas a la estética"28. Por lo que a España se refiere, Pardo Bazán dirá años después, en su largo estudio sobre Tolstoi, que la literatura rusa, en concreto la de Tolstoi, ha tenido lectores pero no discípulos dispuestos a sufrir una supuesta influencia; "las enseñanzas de Tolstoi -dice- no han encontrado eco" 29 . Por curiosa coincidencia, lo que mueve a Pardo Bazán a declararse fervorosa admiradora de la novela rusa no es tampoco una razón estética sino un motivo sentimental y religioso, a saber: el paralelismo étnico que encuentra entre Rusia y España, entre el "mujik moscovita y el labriego de mi provincia gallega", el "dualismo ruso", causa como en España "de sus zozobras políticas y morales", y, sobre todo, su valoración de lo religioso, que ella compagina con el nihilismo y el espíritu revolucionario y su humanitarismo evangélico ${ }^{30}$.

George Portnoff, que estudia extensamente la novela rusa en España, se cuestiona el silencio casi total de la crítica española anterior a 1898 con respecto a los escritores rusos, aunque las traducciones de sus novelas abundan desde $1888^{31}$. ¿A qué achacar este fenómeno? No, por cierto, a inadvertencia. Más bien creemos que la crítica nacional, al juzgar el influjo de la novela rusa en la española como levísimo e intrascendente, lo silenció aunque no con poco rigor. En suma, no creemos que se puedan adscribir propiamente al movimiento iniciado por el realismo ruso ni Galdós -aunque se encuentran ciertas coincidencias temáticas-, ni Pardo Bazán, a pesar de su mayor proclividad hacia lo foráneo.

Por todo lo dicho anteriormente nosotros optamos por establecer la filiación de la corriente espiritualista española de fin de siglo dentro del ambiente general de la época, que en cada país reviste caracteres y dimensiones peculiares. A esto hay que añadir una especie de compromiso y de obligada fidelidad a la tradición nacional, representada en este caso por Cervantes y por los grandes escritores místicos. Hay que convenir, por otro lado, en que el fin

28 Clarín enumera todo un repertorio de causas, a saber: "El deseo de atraer al gran Imperio del Czar a una alianza contra Alemania; la complacencia maliciosa de oponer a los novelistas del naturalismo francés triunfante, otro naturalismo y otros grandes ingenios que eclipsaran a los de casa a ser posible (porque la envidia triunfa hasta de la vanidad patriótica francesa). Añádanse a estas causas la influencia singular de Turguenev, ruso afrancesado, v la crítica estético-moral, suave, clara, simpática y al alcance de todos, de Melchor de Vogüé, el gran propagandista en Francia de Gogol, Tolstoi, Dostoevski y otros pocos rusos" (Ensayos y revistas, Madrid, 1892, p. 223).

29 Obras completas, t. 3, p. 1519.

30 La Revolución y la novela en Rusia, pp. 39 y 64 .

31 La literatura rusa en España, pp. 36-37 y 51. 
de siglo marca en los escritores de la Restauración la hora de una psicología profunda en la novela. Ésta deja de ser un cuadro descriptivo para convertirse en un cuadro de almas, en el que hay rasgos obligados de esa tradición literaria. Tal sucede, por ejemplo, en Angel Guerra y Nazarin. Estos relatos, aparte una mayor interiorización de las sustancias narrativas, vienen a ser verdaderos poemas caballerescos a lo humano-divino en los que aparecen desarrollados gérmenes religiosos y místicos del espiritualismo español. Bien dice Valera que "nadie penetró nunca más hondo" en el alma humana como los místicos. Muchos siglos antes de que Freud elaborara su teoría del psicoanálisis, los místicos habían experimentado una visión en profundidad de la realidad metafísica y metapsíquica que constituye la estructura interior de la persona. Por eso el autor de Pepita Jiménez llega a considerar la lectura de los místicos como "muy útil ejercicio para los escritores de novelas" 32 . Los mismos escritores rusos y, en particular, la generación decadentista francesa ven en los místicos, a quienes leen apasionadamente, no sólo su destreza en él análisis psíquico, sino también otro matiz que cual iluminación súbita los atrae: el espíritu de inquietud e insatisfacción del místico, su idealismo nada contenido, que se niega a contemporizar en muchos aspectos con las estructuras de la religión establecida. Bien conocidos son los incidentes en que algunos de nuestros místicos se vieron envueltos con la jerarquía eclesiástica y aun con la misma Inquisición. San Ignacio de Loyola, ambos Luises, Santa Teresa ${ }^{33}$ y San Juan de la Cruz resaltan entre otros. No sería aventurado decir que los místicos señalan, hasta cierto punto, una profundización en la fe que en su origen está al margen de la religión institucional. Todo esto sirve también para comprender mejor la producción galdosiana que va de Angel Guerra a Misericordia. Guerra y Leré, Nazarín y Halma, y la misma Benina son, salvatis salvandis; místicos a su modo - un misticismo en el nivel humano que tiene en cada uno de ellos sentido y dimensión propios- que actúan impulsados por la fiebre sublime de un ideal evangélico a la vez que profundamente humanista, equidistante de la mística antinatural y en exceso espiritualizada de la religión oficial y de la mística pervertida y amoral de los decadentes.

Desde un plano más ortodoxo, doña Emilia presenta con acento inspirado en el comportamiento de Carmen Aldao, la protago-

32 Obras completas, t. 2, Madrid, 1942, p. 634.

3: Rafael Ferreres, que estudia ampliamente la influencia del simbolismo francés en los modernistas peninsulares, dice que "del católico Paul Verlaine muy probablemente le llega a don Antonio Machado, como a los otros modernistas, su interés y admiración por Santa Teresa de Jesús" (Verlaine y los modernistas españoles, Madrid, 1975, p. 154). 
nista de Una cristiana y La prueba, el ideal de la mujer heroica y cristiana, pero sin énfasis, que frena el excesivo vuelo del espíritu con las insoslayables y lícitas exigencias de la materia. Es decir, en ambas novelas se rubrica, más que la supremacía del espíritu sobre la materia, la feliz conjunción de ambos en el perfil humano del personaje. Porque esta humanización, que es una constante en las obras galdosianas, no está ausente de las obras de doña Emilia.

Walter $T$. Pattison, al hacer referencia a este período de fin de siglo en la literatura peninsular, subraya que "el movimiento hacia la espiritualidad puede considerarse, hasta cierto punto, una evolución indigena de tendencias nacionales" ${ }^{34}$. Efectivamente, teniendo en cuenta el substrato de la tradición y el impulso de la propia individualidad artística, que forman el esquema literario de Galdós y de Pardo Bazán en esta fase, hay que decir que, por todo ello, la huella tanto de la novela rusa como la de las corrientes decadentistas francesas no llega a calar sensiblemente en la obra de nuestros escritores. Esto hay que entenderlo con referencia a la generación de la Restauración, pues en lo que respecta a las promociones posteriores Clarín señala implacable en 1892 que no ve por ninguna parte síntomas de que los literatos jóvenes se hayan enterado de lo que pasa por el mundo ${ }^{35}$. Empero, al referirse previamente a la generación de Galdós y de Palacio Valdés, que sigue la "tendencia espiritual" española, dice que ésta no necesita "copiar análogas manifestaciones de franceses, ingleses o rusos, los cuales obedecerán también a causas semejantes, pero sin perjuicio de la independencia ideal de todos. Así como es absurdo atribuir, a lo menos exclusivamente, tal movimiento de la filosofía y la literatura francesas en sentido que puede llamarse más idealista a la influencia de tres o cuatro novelistas rusos, también sería irracional quitar valor propio a las tentativas de reacción espiritual, en cierto sentido religioso, que van apareciendo en el arte español literario en sus más recientes manifestaciones". Clarín se está refiriendo concretamente a $L a f e$, de Palacio Valdés, y a Angel Guerra, novelas que no considera como fruto de "una imitación más de lo que pasa en París" en la última década de siglo (ibid., pp. 372-373).

34 El naturalismo español, Madrid, 1969, p. 147.

35 Ensayos y revistas, p. 396. Aparte el deseo de arremeter que caracteriza a Clarín, no está clara la razón o razones de esta postura, la cual parece coincidir con la de Pardo Bazán. Porque también doña Emilia emite un juicio nada favorable a la nueva generación al decir que "el expresivo síntoma de que no aparezca aún la generación que ha de continuar nuestras tareas, basta para prueba de que no son aprensiones de cansado veterano las que nublan nuestros ojos y apagan nuestro entusiasmo, precisamente cuando necesitaríamos valor y estímulo para luchar con esta postración y regenerarlo todo". Nuevo teatro critico, 30 (1893), p. 309. 
Por lo demás, la crítica actual no ha tenido en cuenta que lo que en Francia es una violenta reacción neoidealista que agranda la división entre dos generaciones, la de Zola y la de la promoción finisecular -e incluso dentro de aquélla-, en España es una evolución ascendente y sin rupturas dentro de los mismos escritores que se inicia en la fase propiamente naturalista y llega a su punto máximo en el esplritualismo de sus últimas obras. Clarín considera que hacia 1887 el naturalismo es, en cierto sentido, una antigualla en Francia ${ }^{36}$, pero dos años después se rectifica y dice que este movimiento está lejos de haberse agotado, en particular en España. Por su parte, estima oportuno "seguir alentando" esta tendencia pero "con las atenuaciones que imponga el genio variable de nuestro pueblo... y con las que vayan indicando estas últimas corrientes", a las que considera -empleando palabras de Zola- como "una expansión y un apaciguamiento". Realidad, de Caldós, le parece un reflejo español de esa nueva etapa ${ }^{37}$. Justo es señalar que esas "últimas corrientes" a que alude Clarín en un sentido amplio son, como en otro lugar dice, "muy otra cosa, y mucho más, que el capricho de la moda estética de París y aun mucho más que la influencia rusa capitaneada por de Vogüée. Pues se trata de una tendencia que "en general puede llamarse idealista" y que "abarca a muchos países, a muchas clases de actividad intelectual, y tienen derecho los que la siguen originalmente, con la verdadera y única originalidad posible, que es la espontaneidad y la personalidad, a que no se les tome por imitadores de nadie"38. Precisamente, Clarín se está refiriendo, entre otros, al caso concreto de España, donde un grupo de escritores de su generación, en el que destaca Galdós, ha iniciado con gozosa sorpresa para la crítica y para la masa lectora un peculiar movimiento espiritualista y psicológico que crece sin pausa dentro de la corriente realista y que marca el nuevo canon cstético aplicado a las novelas de este período. A Realidad Galdós suma Angel Guerra y Pardo Bazán inicia una nueva andadura con Una cristiana y La prueba.

En resumen, sin desechar totalmente las posibles evasiones a predios ajenos, hay que decir que las influencias externas ocupan menos espacio en las obras de nuestros escritores que el espíritu de la épnca y el genio peculiar de cada uno, y que en éstos y no en aquéllas se encuentra lo intrínsecamente grandioso de sus obras. Y es que para estos escritores del siglo xIx la tendencia espiritualista representa una depuración del realismo español, abierto a las insoslayables exigencias de su tiempo pero reflejando siempre una atmós-

36 Nueva campaña, Madrid, 1887, p. 217.

37 Galdós, pp. 207-208.

38 Palique, p. 168. 
fera específica, estética y temáticamente nacional. Sin subestimar los grandes logros conseguidos durante su etapa naturalista, que ahora se ve como una fase experimental y de aprendizaje, en la nueva etapa rebasan lindes hasta entonces no franqueadas en el plano creacional. Como reflejo de esta etapa el naturalismo y el espiritualismo, no divorciados sino integrados en un mismo molde, logran construir un arte sumamente apto para captar la realidad entrañable y significante que subyace en la dimensión psíquica del compuesto humano.

No se puede negar que esta tendencia realista-espiritualista española tiene como núcleo, como signo común, el espiritualismo cristiano. En el caso de Galdós está teñida de un racionalismo atemperado, pero que sigue siendo al fin cristianismo sólido aunque se desvíe con frecuencia del que enseña la teología católica ${ }^{39}$. A pesar de sus dudas - "Pereda no duda, yo sí" 40 - o quizá a causa de ellas el alma de don Benito es, según Pardo Bazán, "tal vez más cristiana, mucho más cristiana de lo que él mismo sabe y cree" 41 . La crisis de conciencia que a finales de siglo experimentan Clarín y su paisano y amigo Palacio Valdés, sitúa a ambos dentro del espíritu, francamente católico, que si bien no ortodoxo en el primero, no es por eso menos sincero y profundo. En 1889 Clarín escribe lleno de sentimiento religioso a la vez que patriótico: "Yo no concibo un buen español, reflexivo, que se considere extraño al catolicismo por todos los conceptos. ¡Ah!, no; sea lo que sea de mis ideas actuales, yo no puedo renegar de lo que hizo por mí mi madre. Mi historia natural y mi historia nacional me atan con cadenas de realidad, dulces cadenas, al amor del catolicismo... como obra humana y como obra española" 42 . En términos semejantes se expresa Palacio Valdés en carta a Clarín a raíz de su propia conversión: "Deseo de corazón que coincidas conmigo en el acatamiento y el

30 El hecho de que Galdós no participara - probablemente- de la fe religiosa según la teología católica, no justifica que hayamos de excluirlo de su espíritu.

40 Discursos leidos ante la Real Academia..., p. 154.

41 Polémicas y estudios literarios, p. 184.

42 Ensayos y revistas, pp. 196-197. El prólogo de Clarín a la edición de Cuentos morales (Madrid, 1896), pp. vii-viii, desvela un poco el secreto de su biografía espiritual cuando dice: "Cómo entiendo y siento yo a Dios es muy largo y algo difícil de explicar", misteriosa declaración que descifra más abajo con palabras que prueban cuánto priva Dios en su afectividad y que parecen arrancadas de una página de Unamuno: "Mi leyenda, mis ensueños de la Idea Divina, ya empezaron cuando empezaban mis ensueños amorosos, de don Juan por dentro..., y a todas mis Dulcineas las he ido siendo infiel: y mi leyenda de Dios queda, se engrandece, se fortifica, se depura; y espero que me acompañe hasta la hora solemne, pero no terrible, de la muerte". 
amor que debemos, y que sé que tú sientes cada día más, a la sabia religión en que Dios nos ha hecho nacer ${ }^{43}$ ". En el caso de la condesa de Pardo Bazán, para quien "no hay más moral que la moral católica" 44 , huelga aducir testimonios que certifiquen la actitud cristiano-católica de la que en todo momento parte. Los cuatro, aunque cada uno desde su moral e ideología propias y sin dejar de ser siempre ellos mismos, ven en el espiritualismo cristiano un principio fecundo de insospechadas dimensiones para su arte.

Evidentemente, esta filosofía básicamente cristiana de la que parten, la cual se enfrentó desde un principio al naturalismo materialista que había descartado lo espiritual como sector superado en la edad positiva, es algo muy distinto del espiritualismo ruso, mezcla de fatalismo y pesimismo, que por otros caminos lleva también al materialismo y a la nada, y del morboso idealismo y misticismo erótico de las promociones decadentistas, en su mayoría amorales o descreídas.

Estos escritores, al acentuar el valor de lo espiritual y de lo moral, abren estratos muy hondos del ser humano, reservados hasta entonces a los teólogos y psicoanalistas. Junto con el deseo de captar fielmente las realidades biológicas y existenciales sienten la necesidad de penetrar en el complejo mundo de la psique para estudiar el comportamiento humano al "poner en lucha tendencias egoístas animales de nuestra naturaleza con el sentimiento de amor y de justicia que reside igualmente en nuestra alma", como dice Palacio Valdés. Recordaban, sin duda, que en todos los tiempos la mejor literatura siempre ha destacado, continúa el mismo escritor, "las peripecias de la eterna batalla librada entre nuestro ser espiritual y las fuerzas ciegas subterráneas que aspiran a tenerle prisionero entre la bestia y el ángel" 45 . Dentro de esta misma línea de pensamiento, Pardo Bazán ya en La cuestión palpitante había advertido el Escila y el Caribdis que el arte de la época tenía que sortear: el concepto positivista, que confunde lo real con lo tangible y fenoménico, y el "aleteo vertiginoso" del idealismo de Hegel en el que parece que "nos hemos apartado de la tierra y que nos hallamos en las nubes, dentro de un globo aerostático" (p. 44). Piensa doña Emilia que "la esfera, real también, de lo suprasensible, no la conoce el arte sino al través de la humanidad". El naturalismo, en cambio, tenía en parte razón al pretender descubrir la realidad a través de un temperamento. Para hacer válida esta experiencia y salvar las distancias Pardo Bazán sugiere que "sustituyamos ... a la palabra 'temperamento', la palabra 'alma o espíritu', y habre-

43 Adolfo Alas, Epistolario a Clarín, Madrid, 1941, p. 161.

44 La cuestión palpitante, ed. C. Bravo-Villasante, Salamanca, 1966, p. 148.

$4 \overline{5}$ Palacio Valdés, Obras completas, t. 2, Madrid, 1948, pp. 1526-1527. 
mos reconocido uno de los fundamentos de la creación artística humana"46.

Es indudable que el horizonte ilimitado que de esta forma se abre en el mundo del espíritu, contribuye a agrandar y sublimar el arte de nuestros escritores. Niéguese, por ejemplo, esa comunión misteriosa o interacción que en Misericordia se da entre el mundo de la realidad literal y el de la fantasía y habrá que considerar como un desatino estructural el caso esplendoroso de don Romualdo, quedando invertebrada la obra; niéguese el mundo moral y ético, y Carmen Aldao, de Una cristiana y La prueba, nos parecerá una neurasténica, Nazarín un loco de atar, y Benina, la sublime Benina, una paradoja irreducible. Pero para los escritores de estas obras el hombre en su realidad total es un compuesto coherente de cuerpo y espíritu, que ocupa en el universo una posición fronteriza, inmersa por igual en el mundo fenoménico de la materia y en el suprasensible de lo espiritual. Aún más, es dentro de este último donde se encuentra la realidad inconstatable científicamente y la sustancia de las cosas que sólo la intuición del poeta es capaz de captar con ese "ver activo" de que más tarde hablará Ortega. En la tendencia realista-espiritualista encontramos, además, una flexible conjugación entre materia y espíritu, pensamiento y acción que hace viable y saca a la superficie la dinámica profunda del ser humano. Con sensibilidad renovadora que anticipa la novela psicológica moderna, Pardo Bazán dice que no de otra manera es como "el arte nuevo enseña a revelar los interiores movimientos del ánimo por los actos que inspiran; así, y no de otro modo, se manifiesta realmente la vida psíquica, puesto que vemos obrar a todos, y pensar no vemos a nadie. Esto no es materialismo, ni cosa que se le parezca; es una teoría antigua, aplicada con rigor; teoría altamente espiritualista, la de los signos visibles que encarnan lo inmaterial. Por no entenderla algunos críticos, acusan a la novela moderna de descuidar la psicología, acaso nunca tan sinceramente estudiada como ahora"47. Lo que Pardo Bazán dice aquí, refiriéndose al adelanto que el naturalismo había traído al arte al ocuparse del estudio analítico de los personajes y echar mano de los últimos conocimientos de la psicofísica, es de absoluta validez para la moda del día. En algún sentido las corrientes espiritualistas de fin de siglo, que no consideran a la psicología como garte de la fisiología, son, sin embargo, filiales del naturalismo, en cuanto que, como éste, echan mano de los últimos avances de la psicología introspectiva. Bajo este aspecto la deuda del simbolismo y de la novela psicológica con el naturalismo es innegable.

46 La literatura francesa moderna, t. 3, pp. 24-25.

47 Polémicas y estudios literarios, pp. 21-22. 
Volviendo a España y a los escritores de la Restauración que siguen representando la evolución de la novela en la época de entre siglos, hay que señalar el camino propio que estos escritores abren sin solidarizarse en gran medida con lo que pasa más allá de los Pirineos. Desde que en la fase naturalista encauzan su arte hacia una dirección espiritualista, por donde los lleva la fuerza de la tradición y la de sus propias convicciones estéticas, puede decirse que arriban - cada uno con un sello distinto- a unos resultados sorprendentes tanto en el campo de la penetración psicológica como en el de la pura creatividad. Considerada la cuestión objetivamente, es indudable que la intención de ellos es llevar a efecto un acercamiento a la realidad total. Parten de la realidad comprobable para hacer permeable la frontera de esa otra realidad multiforme, vital y cambiante que es lo humano. Esto pone sobre el tapete el complejo tema del realismo literario español, con su inherente naturaleza dualista que, como dice Pardo Bazán, "ríe y llora en La Celestina y El Quijote, en los cuadros de Velázquez y Coya, en la vena cómico-dramática de Tirso y Ramón de la Cruz. ¡Realismo indirecto, inconsciente, y por eso mismo acabado y lleno de inspiración; no desdeñoso del idealismo, y gracias a ello, legítima y profundamente humano, ya que como el hombre, reúne en sí materia y espíritu, tierra y cielo!" 48 . Este concepto español de una realidad amplia y plurivalente va a tener consecuencias resonantes en la obra de nuestros escritores, particularmente de Galdós, como las tuvo anteriormente en Cervantes, por no citar más que al creador de la novela moderna. $O$ sea: este carácter espiritual y humanista de la realidad da profundidad a sus novelas de entre siglos. Así, sobre la urdimbre de una realidad a la vez sensorial y entrañable se teje la trama y se perfila el contorno psicológico y humano de los caracteres. Y es dentro del ámbito y de las modificaciones de esa realidad de múltiples prismas que se encuentra tanto la dimensión estética como el mensaje humano de las obras. Porque hay que convenir en que sería un concepto incompleto de la realidad hacer coincidir ésta con el mundo fenoménico de los sentidos, limitando de este modo la perspectiva múltiple del arte. Al contrario, pues el arte penetra la esfera maravillosa del espíritu y descubre esa otra realidad que configura la compleja textura de lo humano. Hay algo incomprensible y portentoso desde el punto de vista del arte, no menos que desde el de la psicología, en ese laberinto que es la mente de Ángel Guerra, de Nazarín, de Benina, y de Silvio Lago, siempre que se barajan como realidades fluyentes $\mathrm{y}$ ambiguas en una continua transacción entre lo ideal y lo real las 
peripecias materialmente vividas con los pensamientos, los sueños y las alucinaciones. Quiere esto decir que las fronteras de lo real y de lo imaginado, al hacerse permeables, han alcanzado el trasfondo de que se nutre lo humano, o, más claro, que el mundo de la realidad y el de la imaginación son idénticos. Leon Livingstone, que estudia el concepto reversible de realidad e imaginación en la tradición literaria española, al llegar al caso de don Romualdo en Misericordia, trata de explicarlo diciendo que "lo que envuelve esta inversión no es un mero escapismo, una simple idealización o una huida romántica o mística para evadir la realidad, sino un nuevo concepto de lo real, una reinterpretación de la realidad que permite la unión de opuestos al parecer mutuamente contradictorios, transformándolos en facetas recíprocas de una sola totalidad. El aspecto importante de esta nueva fusión de elementos contradictorios es precisamente su reciprocidad. No es que constituyan dos mundos que puedan adaptarse uno al otro por medio de la adición, de la superimposición, o de la alternación, sino que cada uno es simplemente el otro visto desde un punto de vista distinto, de manera que los miles de elementos de la realidad llegan a ser meras facetas de la imaginación, y viceversa. Este es un universo cuya infinita variedad se deriva de la fundamental equivalencia de todos sus ingredientes aparentemente desiguales"49. Ahora bien, lo que hay en el fondo de esta concepción de la realidad, genuina y significante, propia de la literatura española, es la existencia de un forcejeo por resolver un problema que rebasa los linderos de la estética, un problema que es la cara y la cruz del mismo carácter español que, escindido durante gran parte de su historia entre tendencias disociadoras, no ha alcanzado todavía la síntesis armónica entre lo espiritual y lo humano, la fe y la razón, lo antiguo y lo moderno, pero que lucha por alcanzarla. Algo de esto deja traslucir doña Emilia en un espléndido buceo que hace del ser nacional con el sincero deseo de buscar remedio en el arte cuando dice: "Si nosotros -que somos, como Rusia, un pueblo antiguo y a la vez joven, que aún ignora a dónde le empujará el porvenir, y no acierta a poner de acuerdo la tradición con las aspiraciones- consiguiésemos llegar a encarnar en nuestra novela no sólo trozos de realidad fragmentaria, individualismos artísticos, sino el espíritu, el corazón y la sangre de nuestra patria, lo que se elabora, lo que late en todos nosotros, en el conjunto..., a fe que sería bueno, muy bueno"̄o. Galdós, quizá más que ningún otro, se afana en buscar una solución a esta dicotomía que cancera el alma nacional.

49 Tema y forma en las novelas de Azorin, Madrid, 1970, p. 35.

50 La Revolución y la novela en Rusia, p. 276. 
La obra de su última fase está pensada toda ella como una meditación profunda que quisiera penetrar en lo íntimo del problema No concibe que éste se resuelva mientras los intentos de conciliación no graviten en torno a la búsqueda de un mundo más humano en el que materia y espíritu, tradición y modernidad, razón y fe, realidad e imaginación, mutuamente se unan, se ayuden y se rediman $^{51}$.

Mariano López

Mississippi State University.

51 Un ejemplo: Benina encarna la suprema sintesis humana del esquema que Galdós tan perfectamente traza y tan plenamente consigue en Misericordia, novela elaborada "en las entrañas fecundas de la realidad" (Galdós, Obras completas, t. 4, p. 1481), realidad más que nunca significante porque ahora deja al descubierto "la desnudez humana", que -como es bien sabido- es la verdad del arte. 